\title{
Some Reflections on the Impact of Globalisation in the Teaching and Learning of English in Socalled "Expanding Circle" Countries"
}

\author{
ISABEL BALTEIRO \\ Universidad de Alicante
}

Received: 4 November 2010 / Accepted: 6 December 2010

ISSN: $1697-7467$

\begin{abstract}
This article deals with the ongoing debate on the complex role of English as an International Language, be it understood as a homogeneous entity (one language with an international role [EIL]) or a heterogeneous one (different varieties (WE or ELF) grouped under one label, «English») as well as on the implications of this «globalising» status for its teaching in non-native settings. Given the complexity of this phenomenon, whose study is still in its infancy, we attempt neither to provide definitive answers nor adopt a prescriptive attitude, but simply contribute to the discussion and clarification of this, to some extent, emergent, controversial situation. Key words: globalisation, English International Language (EIL), World Englishes (WE), English Lingua Franca (ELF)
\end{abstract}

Reflexiones sobre el impacto de la globalización en la enseñanza y aprendizaje del inglés en el 'Expanding Circle'

RESUMEN: El presente artículo se centra en el debate que viene produciéndose sobre el papel complejo del inglés como lengua internacional, ya sea considerado como un hecho homogéneo (esto es, un solo idioma con una función internacional, o «EIL» en inglés), o heterogéneo (distintas variedades, correspondientes a las siglas inglesas «WE» o «ELF», agrupadas bajo una sola etiqueta, «inglés»), así como las implicaciones de su estatus «globalizador» para la enseñanza en entornos no nativos. Dada la complejidad del fenómeno, cuyo estudio se encuentra todavía en sus albores, no es nuestra intención ni dar respuestas definitivas ni adoptar una posición prescriptiva, sino meramente hacer una aportación al análisis y clarificación de esta situación controvertida $\mathrm{y}$, hasta cierto punto, emergente.

Palabras clave: globalización, English International Language (EIL), World Englishes (WE), English Lingua Franca (ELF)

\section{INTRODUCTION}

It is nowadays an undeniable fact that English is by far the most widespread language in the world. Not only geographical, historical and socio-cultural factors, as

1 According to Jenkins (2000:1), at the turn of the century there were 337 million L1 English speakers and 1,350 million L2 speakers. 
Crystal (1997) mentions, but also political ones, led to the initial spread of English. First of all, the two diasporas (as mentioned by Kachru and Nelson 2001:10), that is, the migrations of British speakers to Australia, New Zealand and North America, as well as the colonisation of other countries such as Asia or Africa. Secondly, the position of England as the leading country as regards industrialisation and trade, especially after the Industrial Revolution, and, therefore, the association of English to the language of advancement and development, whose knowledge was (and still is) required by those who wish to remain up-to-date in the latest technological and scientific issues. All these conditions (namely, historical, political, economic, demographic, technological, scientific, and socio-cultural), reinforced by the role of the media since the late $20^{\text {th }}$ century, positioned English as a global, international or world language ${ }^{2}$.

Linguistically speaking, the globalising character of English may be understood in quite different ways: as a homogeneous or unifying leading language or, on the contrary, as a heterogenous or diversifying one. In other words, on the one hand, a homogeneous position (see Graddol, 1997: 3; or Pennycook, 2003), tends to ignore all the «adaptations» that English undergoes in different countries and sees it as a general international language, which some believe will even lead to the loss of other languages (see Nettle and Romaine, 2000). On the other hand, the heterogeneity approach focuses on the different «Englishes», that is, different varieties or dialects ${ }^{3}$, that arise in various locations but, interestingly enough, scholars defending this approach still look for a homogeneous solution by trying to spread standarization or find standard solutions to the divergences, especially to those causing misunderstandings or miscommunication. As we shall see below, while the former is studied under the «EIL» label, that is, as «English as International Language», the latter gave birth to two approaches, «World Englishes» (WE) and «English Lingua Franca» (ELF). The awareness of this situation is not new. It dates back to 1978, when two outstanding conferences on English as a world language at the East-West Center in Hawai and at the University of Illionois at Urbana-Campaign (on this see Smith 1981 and Kachru 1992) took place. However, the debate concerning the «forms of English» and its «variables» (see Strevens 1981) still continues to this day. At the same time, some pessimistic views about the length of this prestigious state may also be found. Graddol

2 The label «variety» rather than «dialect» is actually preferred in this work, as the term «dialect» has been stigmatized as provincial and not well-educated, which, obviously, has nothing to do with the situations and environments considered here.

3 Kachru (1985) and Kachru and Nelson (2001: 13) provided a classification of countries and users of English in terms of three concentric circles. The innermost circle includes those countries and language users for whom English is the first or dominant language (England, the United States, Ireland, Canada, Australia, New Zealand). The second or «outer « circle is formed by those countries and speakers using English as a second language, mainly as the result of colonisation, and where English has played important roles in education, government, literature and culture, such as India, Nigeria, Pakistan, Singapore, South Africa, Zambia and the Philippines. The expanding or outermost circle comprises those countries where English is not an official language but simply taught as a foreign language to be used for international, scientific, technological or, simply, communicative purposes with speakers of other languages (e.g. continental Europe, Japan, China, Indonesia, Iran, Korea, Nepal and South America). 
(2000 and 2006: 3), for example, claims that «as the number of English speakers expands further there are signs that the global predominance of the language may fade within the foreseeable future», due to varied reasons like «complex international, economic, technological and cultural changes».

In pedagogic terms, interpreting this situation of English as either a globalising language or, on the contrary, as localising Englishes (be these understood as different languages or different varieties) may have serious implications for language teaching. Discussing how this affects teaching goals and what changes in approaches and methods in language learning should take place (or even if changes are to be made at all) is one of the main aims of this article.

\section{ENGLiSH INTERNATIONAL LANGUAGE, WORLD ENGLISHES AND/OR ENGLISH LINGUA FRANCA: THREE LABELS FOR THE SAME REALITY?}

As seen in the Introduction, it can generally be argued that the spread of English as an International Language and the achievement of this globalising status is the result of the migration movements of British peoples to different countries and, consequently, the acquisition of English as a second language, but also of the learning of English as a foreign language. Accordingly, a basic distinction has been made between English as a native language (NE), English as a second language (ESL) and English as a foreign language (EFL). But, apart from these, many equally important labels and approaches have also arisen, amongst others, International English (IE), World Englishes (WE), English Lingua Franca (ELF), etc., which, in our opinion, reflect simply different ways of looking at the same situation, as we shall see below.

We may argue, as Nunn (2005: 70) does, that the implications of English as an International Language are extremely varied. In general, however, the literature seems to restrict the term IE to refer to Standard English, that is, to the variety of the English language which is «normally employed in writing and normally spoken by 'educated' speakers of the language», as Trudgill and Hannah (1995: 1) put it. Nevertheless, this term may also refer to the variety that has been taught to learners of English as a Foreign or Second Language up to the present day. In spite of this, for these latter purposes the label «IE» is nowadays being replaced in many works by that of ELF, to the extent that there seems to be some confusion concerning terminology, because some authors have used it indistinctively. If a distinction is to be made, however, IE is preferred for homogeneous approaches to the language situation, while WE and ELF is used by those who study the localising or diversifying aspects or varieties of English.

Like IE, the term «World Englishes» (WE) has also been used as «an umbrella label» (Bolton 2004: 367) to refer to all the varieties of English worldwide, but it has lately been almost exclusively restricted to so-called «institutionalised English second language varieties», corresponding to former British colonies, that is, to Kachru's so-called «outer circle» varieties ${ }^{4}$. As Kachru himself states, «[t]he result of such uses [in the local

4 Standard English is defined by Richards, Platt and Weber (1985: 351) in The Longman Dictionary of Applied Linguistics as «the variety of a language which has the highest status in a 
educational, administrative, and legal system] is that such varieties have developed nativized discourse and style types and functionally determined sublanguages (registers) and are used as a linguistic vehicle for creative writing» (1986: 19; our emphasis). In spite of Kachru's claim (1992: 2) that the concept world Englishes emphasized «WE-ness,»and not the dichotomy between $u s$ and them (the native and non-native users)», paradoxically enough, one of the most important issues is that these varieties greatly differ from the standard one, as they have been greatly influenced by local languages and cultures and, therefore, they have been considered worth of being studied independently, as varieties of International English (on this see Quirk 1981).

Still, there is a third and apparently quite new approach to the spread of English, that of English as Lingua Franca (ELF). This framework focuses on the English in Kachru's «expanding circle», that is, English as produced by non-native speakers, who study or learn it as a foreign language, in non-native speakers' interactions. As Firth (1996) defines it, the ELF label refers to «a contact language between persons who share neither a common native tongue nor a common (national) culture, and for whom English is the chosen foreign language of communication».

All these three paradigms have naturally had their own and well-differentiated implications for the teaching of English all over the world. Let us provide a very brief account of the differences here (for a more detailed study see Pakir 2009).

While the IE paradigm considers that users are learning a foreign language and the focus is on language proficiency, accuracy and efficiency, following a native speakers' model, the WE and the ELF paradigms pay attention to the adaptations that English undergoes in different non-native settings, environments and communicative situations among non-native speakers, that is, they concentrate on how much the arising "varieties» or linguistic productions differ from the so far considered standard or native model. Furthermore, these two approaches seek variety recognition, either in the outer circle or in the expanding one, respectively. Note also that WE have nowadays some reputation and many of the so-called second language varieties have already been amply described and consequently recognised. ELF, however, has still a long way to go, despite the efforts by scholars like Canagarajah (1999, 2005), Jenkins (2000, 2004, 2006), Mauranen (2003a, 2003b), McKay (2002), Pennycook (1999), and Seidlhofer (1999, 2001, 2004), amongst others, especially as regards a radical pedagogical change in the English language classroom or simply as an alternative to the IE approach.

Thus, it appears that, as Pakir (2009) also suggested, the well-established and amplyacknowledged IE paradigm is being challenged by the WE and, especially, by the ELF paradigms. While the WE perspective seems to have already found its position, ELF is currently making a great effort to gain recognition. The question may then be, as Pakir (2009: 228) posits it, whether these are competing or complementary paradigms. In our view, it seems that WE and ELF (or ESL and EFL) try to gain acceptance and are,

community or nation and which is usually based on the speech and writing of educated speakers of the language». This is not only that with the most prestige but generally used in the news media and in literature, described in dictionaries and grammars, and taught in schools and to non-native speakers when they learn the language as a foreign language. 
therefore, in that sense competing paradigms trying to replace Standard English (note that this struggle is at least as old as Boonlau Debyasuvarn's (1981) outstanding article, «Will EIL succeed where ESL and EFL fail?»). However, it is our belief that WE and ELF are simply different labels for the well-known ESL and EFL approaches, and are used depending on whether English is considered from the point of view of the users or learners of the language, or of that of language use or practice, respectively. In the end, such differences are most probably only useful for mere theoretical linguistic analyses and purposes. The actual reality and features of English in outer circle and expanding circle contexts present, to some extent, similar differences in vocabulary, grammar, pronunciation, etc. if compared to any native English or also to the so-called Standard English.

Apart from that, we still consider that the role of English as one unique language has to be emphasized, regardless of the so-called different "varieties» that may arise in the outer circle and of the adaptations or interferences of non-native speakers in the expanding circle. If we view native varieties like American English and British English as simply «English», why shouldn't one regard as simply «English» those spoken (with more or less interferences or adaptations) in the outer and expanding circles? Still, if one is to accept the differences, shouldn't we simply speak of WE vs. native English (NE), and WE would include outer and expanding circle «varieties»?

To conclude this section, we would like to argue that English should be considered as one and a single language with an international role worldwide and, therefore, spoken by native and non-native speakers, who live in different places and who, consequently and naturally, introduce («local» or idiosyncratic) variations or adaptations in the language (on this see Quirk 1981). These variations are obviously linguistically interesting, but this situation should not imply emphasizing the differences, as this would lead to a paradox and, in our opinion, to an undesirable situation of completely divergent development of the language, language fragmentation, and, consequently, to the loss of its international role as the language, means or communication link among speakers who do not share another language.

\section{GLOBALISATION AND ITS IMPACT IN THE TEACHING OF ENGLISH WORLDWIDE}

In the past, the spread or globalisation of English and its role as an international language generated an important demand for teachers and for language learning in native and non-native English settings by non-native speakers from different countries and nationalities. English was then (and still is) taught following the native speakers' model, either in its British or American standard varieties and accents ${ }^{5}$, that is, Received

${ }^{5}$ Following Crystal's argument that «why a language becomes a global language has little to do with the number of people who speak it. It is much more to do with who those speakers are.» (1997: 5; our emphasis), defenders of the ELF approach claim that most of the English spoken and written daily around the world is produced by non-native speakers of the language. In fact, communication between non-native speakers represents about 80 percent of verbal exchanges in English (see Beneke, 1991; Crystal, 1997; Graddol, 1999; and Gnutzmann 2000). This situation is regarded by Seidlhofer 
Pronunciation (RP) or General American (GA), respectively, which were considered the most prestigious varieties worldwide. RP seemed to be the most generalised variety or accent at least until the end of the $20^{\text {th }}$ century, when American English became more prominent, especially due to the media (cinema, television, etc.), and when the importance given to RP was questioned. In fact, scholars like McArthur (1992: 851) claimed that «[i]t has always been a minority accent, unlikely ever to have been spoken by more than 3 $4 \%$ of the British population». But, apart from the dichotomies on what native variety and on what native accent should be taught, there arose other (now historical) debates on the approaches and methods and, consequently, on the labels to be used. TESOL (or Teaching English to Speakers of other Languages), ESL (English Second Language) and EFL (English Foreign Language) were the most remarkable ones. ESL or EFL were the first labels used to refer to the English taught to non-native speakers or learners either in England or any other country in which English is the first language. The main aim was achieving native-like proficiency, a position that is completely understandable because native speakers are felt as «the model» to be imitated and so it has been for a long time. But ESL or EFL were also later similarly taught in non-native settings. Thus, in countries such as Spain, English was and still is taught and learnt assuming that native speakerlike proficiency and accuracy is also expected from non-native speakers.

It is to be noted that, while the labels ESL and EFL have been indistinctively used for a long time, they have recently been clearly differentiated due to the globalisation of English and the new emerging approaches, following Kachru's concentric circles. Accordingly, ESL is now mainly used in the literature to refer to the English taught and learnt in the outer circle, in principle as a second language, while EFL applies to English from the expanding circle countries where English is said to be used or learnt as lingua franca. In our opinion, this distinction should not be taken literally, as English may not generally or actually be, literally speaking, the second language of learners in the outer circle, as users may have another language as the second one for family or any other unpredictable reasons.

Apart from that, in the search for native-like proficiency many more or less controversial methods have been used. Amongst others, the following may be shortly mentioned: direct method, audiolingualism, grammar-translation method, suggestopedia, silent way, and communicative methods. Nowadays, however, regardless of the approach used to teach English, that is, following the native model and/or looking for native-like proficiency or not, communicative methods seem to be preferred: effective and intelligible communication or interaction appears to be the aim and target of any language learner and/or teacher.

Then, while at first, when English began to spread, the worldwide question seemed to be mainly how it should be taught to achieve native-like proficiency in standard English, nowadays with the absolute globalisation of English and its undeniable international role at all effects and for all purposes, the emphasis in expanding circle countries is now on what to teach for effective and intelligible communication, regardless

(2004:209) as «a state of delicate balance, or what physicists call 'unstable equilibrium'», referring to the fact that the majority of the world's English users are now found in countries where English is a L2 but still native speakers control the norms of the language. 
of how proficient or accurate the speaker may be. Mistakes and/or errors are generally disregarded and only paid attention to when they produce miscommunication problems. Furthermore, the question of which variety or accent is best or most prestigious does not seem to arise anymore, as it is not expected that users acquire an accent different from their own native one, which is transferred to their productions in English as a lingua franca. This emerging approach, English (as a) Lingua Franca, does not consider it appropriate to teach English aiming at native-like proficiency, as it is believed that users of ELF will have very scarce opportunities of using the language with native speakers. Instead, it is claimed that they will have to communicate in many unpredictable situations with non-native speakers from the most varied cultures and settings. Therefore, the objective of these emerging approaches to teaching English is knowing linguistic particularities, adaptations and cultural issues as well as aiming at intelligibility, comprehensibility and interpretability in non-native interactions. The question is then whether a new model or a new standard, different from the native speaker's one, should be aimed at, but also if this would mean the end of EFL or not (on this see Graddol 2006) or rather, if an EFL approach does no longer hold.

\section{THE NEED FOR A NEW PEDAGOGIC MODEL}

As has been discussed in the previous sections, there is at present an ongoing debate, especially in the ELF approach, on the teaching of English to non-native speakers from the expanding circle countries, given this globalising or international status and cross-cultural role of the language ${ }^{6}$. Lingua Franca theoreticians claim that a change in English teaching from a norm-bound approach to one that focuses on communication, intelligibility ${ }^{7}$, mutual comprehensibility and cultural identity (see Sifakis 2004) is called for, as they believe that the possibilities of interaction with native speakers of English are reduced to a minimum in cross-cultural communication (see also Footnote 5). Thus, learners or users should no longer aim at the native speaker's model or proficiency. Accordingly, Kirkpatrick (2007:188) argues that teaching a native speaker model, based on inner-circle pragmatic norms and cultures, is not appropriate for «many» learners in the countries of the other circles. In his view, there are three models to choose from when it comes to language instruction, namely, the exo-normative native speaker model, the

${ }^{6}$ Intelligibility may be defined as «the extent to which a speaker's message is understood by a listener» (see Munro and Derwing, 1995). However, Smith (1992) views it on a continuum in terms of degrees of understanding, with intelligibility being the lowest and interpretability the highest: intelligibility being the ability of the listener to recognise individual words or utterances, comprehensibility the listener's ability to understand the meaning of the word or utterance in its given context, and interpretability the ability of the listener to understand the speaker's intentions behind the word or utterance (see Smith and Nelson 1985). Note that Jenkins (2000) also remarks its importance by considering intelligibility as a prerequisite (though not a guarantee) for successful communication.

7 Unlike ELF scholars, it is here believed that still (future) teachers and translators or even ESP learners, for example, are expected to have a high degree of or native speaker-like oral proficiency, accuracy, fluency and knowledge, as they are desirable for their professional purposes. 
endo-normative nativized model, and, in certain contexts, the lingua franca model (see Kirkpatrick 2007: 184, and also McKay's discussion (2002: 34-47) on the inappropriateness of native competence as a goal of EIL). Errors, mistakes, or even «local» non-native accents, for example, are no longer criticised or looked down on, but welcome provided they do not produce communication problems. Nevertheless, as a result of this latter requirement, ELF followers still believe it necessary to obtain a language core or model of language to maintain a certain degree of standardization, which should contain the rules to ensure intelligibility, comprehension and effective communication between users, which is, after all, the final aim of any interaction. This seems to be especially important if, as Seidlhofer (2004) claims, multilingual speakers adopt independent norms to achieve intelligibility. Furthermore, these theories tend to emphasize the importance of including cultural matters and issues in the teaching or learning of English. In other words, divergences and variations from the native norm (considered as errors or mistakes and as a sign of a lack of knowledge or ignorance of the rules of the language in traditional approaches), non-native English localisms, etc. are not to be eradicated within this framework or paradigm as far as communication is maintained. Accordingly, a new model seems to be necessary. But, is it desirable? Is it feasible? Does it actually make sense to look for a new model?

To begin with, it is our belief that the ELF approach derives from an erroneous premise, namely, that learners or users of English in the expanding circle may never communicate or need to interact with as many native speakers of English as they do with non-native speakers of such language. It obviously all depends on the situation of each individual. There are three situations which may immediately come to our mind immediately in which communication with native speakers cannot be discarded: a person from the expanding circle may (1) move to and/or live (permanently or not) in a native English country, (2) travel to native English speaking countries for business or leisure purposes, (3) meet and interact with English native speakers in other non-inner circle countries.

One might also disagree with the idea that speakers of English from the expanding circle will never be as competent in English as others from either the outer circle or even from the inner circle (on this see also Modiano, 1999). If one simply thinks of a noneducated native person versus a well-educated and cultivated person from the expanding circle, one may probably conclude that it is most than probable than the non-native English person can write in English with more accuracy than the native (e.g. the writer Joseph Conrad). Being more or less competent or proficient in a language cannot only depend on a person's origin or on the place or country where a person lives, as the ELF paradigm seems to consider. It all depends on many personal, professional, educational, and other circumstances. Besides, one can easily imagine that, in specialized registers, a non-native might achieve a much higher degree of competence than many native speakers; for instance, it would not be surprising to see a judge from an expanding circle country sitting at an international court with a command of legal English far greater than that of the majority of inner circle speakers.

In relation to this, a distinction should be made between written and oral communication. It is certainly the case that in oral interactions, as the ELF approach claims, the most important aim should be getting the message across, making it intelligible, regardless of 
the errors or mistakes that may occur ${ }^{8}$. In written communication, nevertheless, especially in academic contexts and specialized and internationally recognised publications, strictly following the norm is still required and errors or L1 interferences should be avoided, as they may cause papers or books to be rejected. In fact, in academic publications guidelines can be found like «If you are not a native speaker of English, please have your contribution carefully checked by a native speaker» (Style sheet for Mouton Journals, 2008). Even in less specialized writings like, for instance, a business letter, if the native norm is not followed a bad impression may be caused to our interlocutor. It is not our intention to predict here whether it is a question of time or not or whether the norms should be relaxed (or not) but we still do not find reasons to do so and replace the native model for an apparently «more realistic» one. Moreover, if ELF also seeks some kind of standardization and a language core, why should the present and perfectly valid model be abandoned? What benefits would be obtained from a new and more relaxed or flexible (and probably to some extent deficient ${ }^{9}$ ) model? Wouldn't that new model even complicate matters? Wouldn't it make English change to such an extent that native speakers might not recognise the language or the emerging «Englishes»? Wouldn't it be the case that, if one accepts «local» varieties, that is, a good number of interferences from every single linguistic background, it would derive in complete unintelligibility ${ }^{10}$ and so arrive at a paradoxical situation (after all, the ELF framework aims at intelligibility!)? Therefore, ELF claims should, first of all, distinguish written from oral communication settings, and, secondly, rethink how far one can go in allowing the traditionally called «interferences» from the expanding circle's different linguistic backgrounds, and if it is advisable to emphasize those varieties. In our opinion, those varieties, interferences or adaptations should be linguistically analysed in the literature so that miscommunication problems may be identified in order to find solutions and consider them in our teaching, and sometimes even with the aim of telling other learners from other linguistic backgrounds about them, as Sifakis (2006) remarks ${ }^{11}$. One might question the usefulness of making a great effort on the part of the learners to know both linguistic and cultural characteristics, variations,

${ }^{8}$ Similar to these are Holliday's (2005, and 2008: 124) claims that it will not be easy to teach English as an international language or ELF as this might be seen as an attempt to impose what he calls an «inferior» model on the «periphery«.

9 Unlike this, see Widdowson (1994: 385), who argues that «[i]t does not follow logically, however, that the language will disperse into mutually unintelligible varieties. For it will naturally stabilize into standard form to the extent required to meet the needs of the communities concerned.» McArthur (1998, 2003), however, suggests that a move towards «hybridisation» represents a normal process of world languages.

10 Sifakis (2006: 156) argues that learners should be exposed to and become actively aware of as many and diverse samples of non-native speakers (NNS) discourse as possible, and acquire training in making themselves comprehensible in as many different communicative situations and with as many different types of NNS as possible.

11 Note, however, Kirkpatrick's (2007:193-4) shortlist of three issues to be considered for a potential curriculum within the ELF Framework: (1) Students would need to be alerted to which linguistic features cause particular problems of mutual intelligibility; (2) The curriculum would need to focus on how cultures differ and the implications of such differences for cross-cultural communication (facework, appropriate request schemas); (3) Students would need to be taught the communicative strategies that aid successful cross-cultural communication. 
and interferences that other expanding circle users produce, although, obviously, it may be worth doing so with certain learners and for very specific purposes, e.g. conference interpreters, or those about to engage in international negotiations with a given group of non-native speakers. Apart from that, another solution would be creating or finding a common core, which not only seems to be «impossible (...) for other language levels except for the phonological one» (Jenkins, 2000) but also appears to us as a timeconsuming activity for two reasons: first, it would imply analysing large amounts of data (as present-day corpora such as VOICE try to do), which would have to be described in order to substantiate prescription, and hence attempt to standardize on the basis of such prescription. Furthermore, as Widdowson (2003: 106) puts it, «linguistic descriptions cannot automatically meet pedagogic requirement». Secondly, if a core were to be obtained, how different would it be from the native norms? Alternatively, efforts may continue to be made to proficiently teach the basic norms to learners worldwide to guarantee intelligibility at a global or international level.

As regards teachers' role, apparently the dilemma native English teacher / non-native English teacher is overcome by the ELF change of focus, since any divergencies from the standard in the teacher's variety would be perfectly acceptable, and even desirable in certain contexts. In fact, Kirkpatrick (2007: 187) points out that universities, even in English-speaking countries, employ «significant number of academics recruited from other inner-circle countries and from many outer-circle ones». One might agree with the principle that a non-native teacher (e.g. a Spaniard teaching English in Italy) conveys the message that English is a lingua franca and encourage students to learn it; indeed, such model is in principle more stimulating than that of a native English teacher, a model technically unattainable for learners (if I, a Spaniard, did learn so much English, you can also do it). However, the real point, in our opinion, is whether the teacher (native or not) is familiar with the learners' native language particularities; back to our example, if the Spaniard is familiar with Italian language and culture in order to anticipate possible problematic areas and be prepared to deal with specific problems, which may contribute to effective and intelligible cross-cultural interactions. In addition to this, defenders of the ELF approach also consider it appropriate, especially due to the proposal of a Lingua Franca Core for pronunciation (see Jenkins 2000), for those teachers who do not feel confident in teaching pronunciation. Apparently, this Core will allow them to gain confidence. However, we believe that this would impose an, at less for the moment, less «acceptable» model and the native norm would still remain as an implicit reference.

Apart from those, other issues, like stress on language negotiation, emphasized in the ELF approach, are not discarded even if a native model is followed, as this and other accommodation strategies are important in any communicative situation regardless of the speakers' origin and native character or not.

Finally, it is also important to distinguish between the concepts of «use» and «code», which seem to be to some extent confused in the ELF framework. That is, English may be used as lingua franca in cross-cultural interactions but, English Lingua Franca is not a code but the result of using a means or tool for communication (in this case, the English language) or rather, the way or situation in which English is used in certain contexts.

To conclude, as suggested above, a new model of English based on the description of expanding circle productions seems neither viable nor necessary or appropriate at the 
moment. Even defenders of this emerging approach think that ELF corpus linguists do not believe in automatic transfer from sociolinguistic description to pedagogic prescription (see Jenkins, 2007). Also, they have to admit, as Jenkins (2007: 238) does, that «[i]t is, of course, too early to talk of teaching ELF as such». Similarly, Kirkpatrick (2007: 193) notes that it is «difficult to describe or codify a lingua franca model as such for the classroom. However, a lingua franca approach based on the goal of successful crosscultural communication could be advantageous to both teachers and students». Nevertheless, it remains to be clarified in what way, because there is the danger that an extreme application of this model, as has been seen, may not necessarily have desirable consequences.

\section{Conclusions AND FURTher RESEARCh}

As seen in the preceding sections, the complex position of English as an international language has given rise to different roles and, consequently, to varied approaches and interpretations, which also have their implications for language teaching worldwide. As, Graddol (2006: 106) remarks, «almost without anyone noticing, the reasons why English is learned have changed and along with that, the ways in which it is taught». More importantly, «[t]hese incremental changes [in the number of learners] have led to a breakdown of the old paradigm of EFL» (Graddol 2006: 106) and it has also led to emerging and controversial approaches as a result of, for example, the role of English as a lingua franca for cross-cultural communication in the so-called expanding circle.

Even though we still fail to see the need to find a new model or standard (different from the native one) for cross-cultural communication in English, we still think it is linguistically interesting and important to study and analyse communication and breakdowns in cross-cultural interactions at discourse level in order to preserve intelligibility and avoid miscommunication problems. However, research on ELF is still in its infancy and so, though radical changes do not seem to be close at hand, we should probably wait to see how many advantages this new approach or paradigm can offer to teachers and learners of English. In other words, this seems to be the right moment to describe what happens in international communication worldwide but not yet to prescribe as to norms and rules or even models. As Canagarajah (2006: 209-210) suggests, to be able to have a paradigm shift, «we have to change our understanding of language learning» and this «we», obviously, implies changing policies and consciousness in both teachers and learners.

To conclude, it should be remembered that the role of English as an international language is undeniable, and it should be emphasized regarding its usefulness as a contact or link language between communities which do not share the same language. Precisely because of this, we believe that for the sake of intelligibility itself (as the focus of ELF approach emphasizes), non-native «local» adaptations should not be excessively reinforced (which is what ELF seems to do at times) as this would probably lead paradoxically to unintelligibility not only among non-native «varieties» but also between native speakers and non-native ones. Quite on the contrary, conflictive problems and adaptations or variations should be searched for (and this is where the ELF paradigm might offer 
invaluable tools) in order to avoid them, especially in those cases which may cause communication breakdowns, and, consequently, we as teachers should try to reinforce worldwide correct and communicatively effective forms and expressions. It is our opinion that the situation is not ripe yet for more drastic approaches. We agree with Graddol (1997: 56) in that it remains to be seen whether English will end up fragmenting into local forms that become unintelligible to one another, whether the the US and British standards will still function as models for usage, or if, probably as a result of the ELF paradigm, these models will be superseded by some «new world standard». In the present situation, and especially due to the digital media, there is no way of predicting what the result will be, and linguists and teachers may only keep track of these changes, but without jumping to conclusions about what an uncertain future might be like.

\section{REFERENCES}

Beneke, J. (1991). «Englisch als Lingua Franca oder als Medium Interkultureller Kommunikation?», in R. Grebind (ed.), Grenzenloses Sprachenlernen: Festschrift für Reinhold Freudenstein. Berlin: Cornelsen \& Oxford University Press, 58-61.

Bolton, Kingsley (2004). «World Englishes», in A. Davies and C. Elder (eds.), The Handbook of Applied Linguistics. Oxford: Blackwell, 367-396.

Boonlau Debyasuvarn, M.L. (1981). «Will EIL succeed where ESL and EFL fail?», in Smith, L. E. (ed.) English for cross-cultural communication, London: Macmillan, 83-93.

Canagarajah, A. S. (1999). Resisting linguistic imperialism in English teaching. Oxford: Oxford University Press.

Canagarajah, A. S. (2005). «Introduction», in A. S. Canagarajah (ed.), Reclaiming the local in language policy and practice. Mahwah, New Jersey: Erlbaum, xiii-xxx.

Crystal, D. (1997). English as a global language. Cambridge: Cambridge University Press.

Firth, A. (1996) «The discursive accomplishment of normality: on 'lingua franca' English and conversation analysis», in Journal of Pragmatics, 26: 237-259.

Gnutzmann, C. (2000). «Lingua franca», in M. Byram (ed.), Routledge encyclopedia of language teaching and learning. London: Routledge, 356-359.

Graddol, D. (1999). «The decline of the native speaker», in AILA Review, 13: 57-68.

Graddol, D. (2000). The Future of English? A guide to forecasting the popularity of the English language in the 21st century.UK: British Council.

Graddol, D. (2006). English Next. Why global English may mean the end of 'English as a Foreign Language'. UK: British Council.

Holliday, A. (2005). The Struggle to Teach English as an International Language. Oxford: Oxford University Press.

Holliday, A. (2008). «Standards of English and politics of inclusion», in Language Teaching, 41, 1: $119-130$.

Jenkins, J. (2000). The phonology of English as an international language: New models, new norms, new goals. Oxford: Oxford University Press.

Jenkins, J. (2004). «ELF at the gate: the position of English as a lingua franca», in A. Pulverness (ed.), IATEFL 2004 Liverpool Conference Selections. Canterbury, UK: IATEFL, 33-42.

Jenkins, J. (2006). «Current perspectives on teaching world Englishes and English as a lingua franca». TESOL Quarterly, 40: 157-181. 
Jenkins, J. (2007). English as a Lingua Franca: Attitude and Identity. Oxford: Oxford University Press.

Kachru, B.B. (1985). «Standards, codification and sociolinguistic realism: The English language in the outer circle», in R. Quirk and H. Widdowson (eds.), English in the world: Teaching and learning the language and literatures. Cambridge: Cambridge University Press, 11-30.

Kachru, B.B. (1986). The Alchemy of English. Oxford: Pergamon Press.

Kachru, B.B. (1992). «World Englishes: Approaches, issues and resources», in Language Teaching, 25: $1-14$.

Kachru, B. B., and C.L. Nelson. (2001). «World Englishes», in A. Burns and C. Coffin (eds.). Analysing English in a global context: A reader. London: Routledge, 9-25.

Kirkpatrick, A. (2007). World Englishes: implications for international communication and English language teaching. Cambridge: Cambridge University Press.

Mauranen, A. (2003a). «The corpus of English as lingua franca in academic settings», in TESOL Quarterly, 37: 513-527.

Mauranen, A. (2003b). «Signaling and preventing misunderstanding in English as lingua franca communication», in International Journal of the Sociology of Language, 177: 123-150.

McArthur, T. (ed.) (1992). The Oxford Companion to the English Language. Oxford: Oxford University Press.

McArthur, T. (1998). The English languages. Cambridge: Cambridge University Press.

McArthur, T. (2003). «World English, Euro-English, Nordic English?», in English Today, 19, 1: 54-58.

McKay, S. (2002). Teaching English as an international language. Oxford: Oxford University Press.

Modiano, M. (1999). «International English in the global village», in English Today, 15, 2: 23-25.

Mouton Journals. (2008), «Style sheet for Mouton Journals», available from: http://www.degruyter.de/ files/down/mouton_journal_stylesheet.pdf, accessed 30 October, 2010.

Munro, M.J. and T.M. Derwing. (1995). «Foreign accent, comprehensibility and intelligibility in the speech of second language learners», in Language Learning, 45: 73-97.

Nettle, D. and S. Romaine. (2000). Vanishing Voices: the Extinction of the World's Languages. Oxford: Oxford University Press.

Nunn, R. (2005). «Competence and Teaching English as an International Language», in The Asian EFL Journal, 7, 3: 61-74.

Pakir, A. (2009). «English as a lingua franca: analyzing research frameworks in international English, world Englishes, and ELF», in World Englishes 28, 2: 224-235.

Pennycook, A. (1999). «Pedagogical implications of different frameworks for understanding the global spread of English», in C. Gnutzmann (ed.), Teaching and Learning English as a Global Language: Native and Non-native Perspectives. Tübingen: Stauffenburg, 147-155.

Pennycook, A. (2003). English-only Europe? Challenging Language Policy. London: Routledge.

Quirk, R. (1981). «International communication and the concept of nuclear English», in Smith, L. E. (ed.) English for cross-cultural communication, London: Macmillan, 151-165.

Richards, J.C., J.T. Platt and H. Weber (1985). Longman Dictionary of Applied Linguistics. London: Longman.

Seidlhofer, B. (1999). «Double standards: Teacher education in the expanding circle», in World Englishes, 18, 2: 233-245.

Seidlhofer, B. (2001). «Closing a conceptual gap: The case for a description of English as a lingua franca», in International Journal of Applied Linguistics, 11, 2: 133-158.

Seidlhofer, B. (2004). «Research perspectives on teaching English as a lingua franca», in Annual Review of Applied Linguistics, 24: 209-239. 
Sifakis, N. C. (2004). «Teaching EIL - Teaching International or Intercultural English? What teachers should know», in System 32: 237-250.

Sifakis, N. (2006). «Teaching EIL - Teaching international or intercultural English? What teachers should know», in Rubdy, R. and M. Saraceni (eds.), English in the World: Global Rules, Global Roles. London: Continuum International Publishing Group, 151-168.

Smith, L. E. (1981). English for cross-cultural communication, London: Macmillan.

Smith, L. E. ed. (1992). «Spread of English and issues of intelligibility», in B. B. Kachru (ed.), The Other Tongue. Urbana: University of Illinois Press, 75-90.

Smith, L. and C. Nelson. (1985). «International Intelligibility of English: Directions and Resources», in World Englishes, 4, 2: 333-342.

Strevens, P. (1981). «Forms of English: an analysis of the variables», in Smith, L. E. (ed.) English for cross-cultural communication, London: Macmillan, 1-15.

Trifonovitch, G. (1981). «English as an international language: an attitudinal approach», in Smith, L. E. (ed.) English for cross-cultural communication, London: Macmillan, 211-215.

Trudgill, P., and J. Hannah. (1995). International English: A Guide to Varieties of Standard English, 3rd edition. London: Edward Arnold.

VOICE (Vienna-Oxford International Corpus of English), available from: http://www.univie.ac.at/ voice/page/index.php, accessed 30 October, 2010.

Widdowson, H. G. (1994). «The Ownership of English». TESOL Quarterly, 28, 2: 377-89.

Widdowson, H. G. (2003). Defining issues in English language teaching. Oxford: Oxford University Press. 